\title{
Non-invasive diagnostic and prognostic evaluation of liver cirrhosis and portal hypertension
}

\author{
Annalisa Berzigottia ${ }^{a, b, *}$, Eyal Ashkenazi ${ }^{\mathrm{a}}$, Enric Reverter ${ }^{\mathrm{a}}$, Juan G. Abraldes ${ }^{\mathrm{a}}$ and Jaime Bosch $^{\mathrm{a}}$ \\ ${ }^{a}$ Hepatic Hemodynamic Laboratory, Liver Unit, Institut d'Investigacions Biomediques August Pi $i$ Sunyer \\ (IDIBAPS) and Centro de Investigación Biomédica en Red de Enfermedades Hepáticas y Digestivas (Ciberehd), \\ Barcelona, Spain \\ ${ }^{\mathrm{b}}$ Ultrasound Section, Centre Diagnostic per la Imatge, Hospital Clinic i Provincial, Barcelona, Spain
}

\begin{abstract}
Cirrhosis is the final stage of most of chronic liver diseases, and is almost invariably complicated by portal hypertension, which is the most important cause of morbidity and mortality in these patients. This review will focus on the non-invasive methods currently used in clinical practice for diagnosing liver cirrhosis and portal hypertension. The first-line techniques include physical examination, laboratory parameters, transient elastography and Doppler-US. More sophisticated imaging methods which are less commonly employed are CT scan and MRI, and new technologies which are currently under evaluation are MR elastography and acoustic radiation force imaging (ARFI). Even if none of them can replace the invasive measurement of hepatic venous pressure gradient and the endoscopic screening of gastroesophageal varices, they notably facilitate the clinical management of patients with cirrhosis and portal hypertension, and provide valuable prognostic information.
\end{abstract}

Keywords: Ultrasound, transient elastography, serum markers, cirrhosis, varices

\section{Introduction}

Portal hypertension is a key event in the evolution of chronic liver disorders when severe fibrosis or cirrhosis develops. Once portal pressure exceeds $10 \mathrm{mmHg}$ (clinical significant portal hypertension - CSPH), patients are at risk of experiencing severe complications such as variceal bleeding or ascites. In patients with chronic liver disease, histopathological examination of biopsy samples has traditionally been considered the gold standard for staging the severity of fibrosis and for diagnosing progression to cirrhosis. However, liver biopsy has important limitations (it is invasive and sampling error is very frequent), and in the last decade many studies have been devoted to the search of non-invasive

* Address for correspondence: Annalisa Berzigotti, M.D., Ph.D., Hepatic Hemodynamic Laboratory-Liver Unit and Ultrasound Section-CDIC, Hospital Clínic, C.Villarroel 170, 08036 Barcelona, Spain. E-mail: aberzigo@clinic.ub.es. methods to diagnose fibrosis and cirrhosis. The ideal test for fibrosis and cirrhosis diagnosis should be safe, easy to perform, inexpensive, reproducible (within patients and between and within laboratories) and should provide an accurate assessment of the degree of liver fibrosis from pre-cirrhotic scarring, through very early and early compensated cirrhosis. The test should be predictive of long term outcomes such as portal hypertension, decompensation, need for transplantation, and death.

On the other hand, HVPG measurement is the gold standard technique to evaluate the presence and severity of portal hypertension. Also in this case some limitations exist, since HVPG measurements are not available in all centers, the technique is invasive and some patients are unwilling to be submitted to it. This is even more relevant when the repetition of the procedure is needed to monitor treatment response. These issues have raised interest to non-invasively determine when $\mathrm{CSPH}$ is present, so allowing defining a patient at risk of developing portal hypertension-related complications. 
The aim of this review is to depict the non-invasive tools used to diagnose and monitor treatment of cirrhosis and portal hypertension (Table 1).

\section{Physical examination}

The cheapest and readily available information to detect cirrhosis and/or of portal hypertension is that obtained by physical examination (Fig. 1). Physical stigmata of liver cirrhosis are: a firm left hepatic lobe [1], gynaecomastia, testicular atrophy, parotidomegaly, features of hepato-cellular failure such as jaundice, vascular spiders, leuconykia, palmar erythema or of hepatic encephalopathy, presence of abdominal wall collateral circulation, ascites, leg oedema and splenomegaly (which can be considered the single most important clinical diagnostic sign of portal hypertension). In addition, hypotension and tachycardia may be found reflecting the frequent hyperdynamic circulation found in patients with cirrhosis.

All these findings can be found in decompensated disease with features of portal hypertension, and are obviously highly specific of the syndrome [2]. However, decompensated cirrhosis does not represent the population where non-invasive diagnosis is more needed, and unfortunately, the sensitivity of physical signs in patients with compensated cirrhosis is low.

As for CSPH detection, in a recent study by our group performed in a homogeneous population of patients with well compensated cirrhosis in which HVPG was measured, none of the physical signs was useful to identify patients with HVPG over $10 \mathrm{mmHg}$. On the other hand spider naevi were independently predictive of esophageal varices [3].

\section{Laboratory tests}

Serum markers of fibrosis have the advantage over liver biopsy of offering a sampling of the all liver, allowing frequent repetition, being far less invasive and having less dependence on professional expertise. Moreover, as we will discuss below, they may reflect the severity of liver fibrosis and predict clinically relevant outcomes. In the following we will focus on the ability of these tests to detect cirrhosis appearance. It is out the scope of the review to analyze in depth the utility of these tests in grading fibrosis.

\subsection{Indirect markers of fibrosis (Class II, simple laboratory tests)}

The diagnostic performance of single or combined hematological and biochemical parameters routinely available, which may "indirectly" reflect (surrogate markers) the effect of fibrosis on the liver has been extensively studied. These include indicators of cytolysis (AST, ALT), cholestasis ( $\gamma \mathrm{GT}$, bilirubin), hepatocytes synthetic function (i.e. INR, cholesterol, ApoA1, haptoglobin, N-glycans), and hypersplenisms due to portal hypertension (i.e. platelet count). These parameters may also be surrogates of inflammation and steatosis, which have a significant predictive value for the progression of fibrosis [4,5].

About 20 numerical scores or indices are reported for parameters which are mostly routine laboratory tests and frequently multiparametric. Among them, Fibrotest and AST to Platelet ratio index (APRI) have been proposed for clinical application [6,7]. The FibroTest, which is a combination of $\alpha 2$-macroglobulin $(\alpha 2 \mathrm{M})$, ApoA1, Bilirubin, $\gamma \mathrm{GT}$, Haptoglobin measurements, is the most validated indirect test for liver fibrosis [8-10]. It has been shown to accurately predict the presence of severe fibrosis/cirrhosis with an AUC of 0.92. APRI has also been found to be a reliable predictor of severe fibrosis/cirrhosis in patients with chronic hepatitis C (AUC: 0.80) [11].

However, a recent meta-analysis of 14 studies examining 10 panels of indirect blood markers in chronic hepatitis C [12], including Fibrotest and APRI, demonstrated that in individual patients they cannot reliably differentiate stages of fibrosis. This makes noninvasive markers of fibrosis still insufficient to "monitor" the evolution of chronic liver diseases. In addition, accuracy of serum markers may be reduced by multiple factors, such as co-morbidity of the patients (connective tissue disease among others) and ongoing drug therapies.

As for portal hypertension, Child-Pugh score and its objective component (albumin, bilirubin, INR) correlate with HVPG [13-15] and with the prevalence and grade of esophageal varices in cirrhotic patients. Interestingly this correlation is observed also in patients with compensated cirrhosis [3], suggesting that a close relationship exists between the structural changes which give onset to portal hypertension and hepatocellular dysfunction. In our study, a model obtained by the combination of biochemical parameters, namely albumin, ALT, and INR, had an area under the curve (AUROC) of 0.952 in the prediction of CSPH [3]. 
Table 1

Non invasive methods currently available to diagnose cirrhosis and portal hypertension. As shown, none of them holds all the characteristics of an ideal method; however, their combination might help overcome the limitation of the individual tests. Nonetheless a "portal sphygmomanometer" is not yet available

\begin{tabular}{|c|c|c|c|c|c|c|c|c|}
\hline & & \multicolumn{7}{|c|}{ Characteristics needed for an ideal non-invasive method } \\
\hline & & Safe & Quantitative & Accurate & Objective & Reproducible & Cheap & Validated \\
\hline \multirow{9}{*}{$\begin{array}{l}\text { Non-invasive } \\
\text { methods } \\
\text { available for } \\
\text { diagnostic/ } \\
\text { prognostic } \\
\text { purposes in } \\
\text { patients with } \\
\text { portal } \\
\text { hypertension }\end{array}$} & Physical examination & +++ & - & - & ++ & ++ & +++ & ++ \\
\hline & Standard & +++ & +++ & + & +++ & +++ & ++ & +++ \\
\hline & Laboratory & & & & & & & \\
\hline & Tests & & & & & & & \\
\hline & $\begin{array}{l}\text { Direct serum markers of } \\
\text { fibrosis }\end{array}$ & +++ & +++ & ++ & +++ & +++ & - & ++ \\
\hline & Transient elastography & +++ & +++ & ++ & +++ & ++ & ++ & ++ \\
\hline & $\begin{array}{l}\text { Ultrasound and Doppler- } \\
\text { Ultrasound }\end{array}$ & +++ & + & + & + & + & +++ & +++ \\
\hline & $\begin{array}{l}\text { Abdominal } \\
\text { CT-scan }\end{array}$ & $+(*)$ & + & ++ & ++ & +++ & + & ++ \\
\hline & Abdominal MRI & ++ & + & ++ & ++ & +++ & + & ++ \\
\hline
\end{tabular}

*Cumulative radiation exposure and subsequent risk should be carefully evaluated [78].

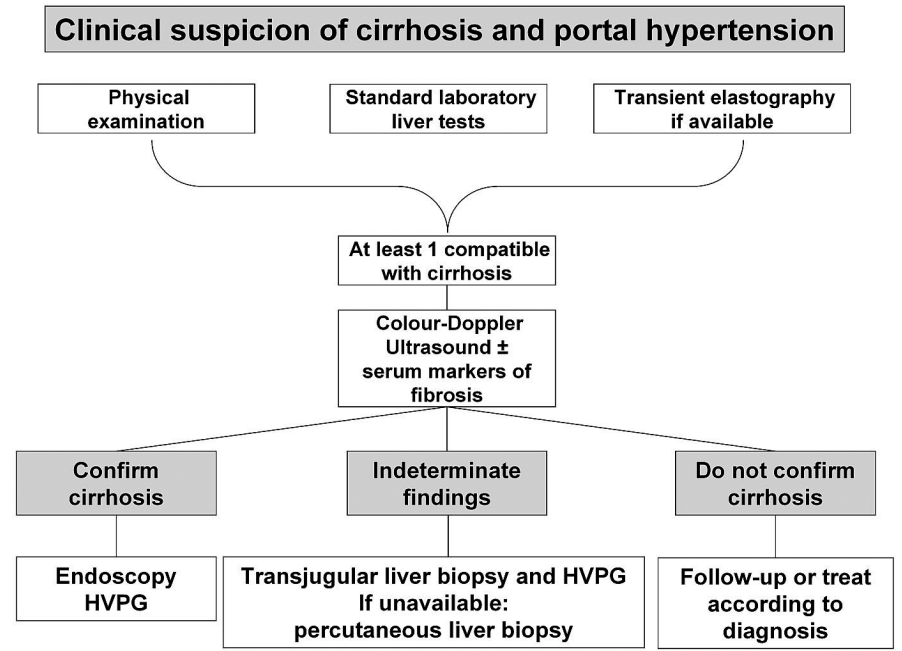

Fig. 1. Proposed algorithm for the non-invasive diagnosis of cirrhosis and portal hypertension. As shown, in indeterminate cases requiring liver biopsy the transjugular modality has to be preferred since this allows the simultaneous measurement of the HVPG. If hepatic vein catheterization is not available a percutaneous liver biopsy should be obtained.

Platelet count is independently correlated with the prevalence and grade of esophageal varices in several studies $[16,17]$, and platelet count to spleen diameter ratio $>909$ had a $100 \%$ negative predictive value for the presence of esophageal varices in one study [18] suggesting that it could be of help in avoiding unnecessary endoscopies; however in subsequent series its predictive value was lower, and should be further investigated before being accepted in clinical practice.

\subsection{Direct markers of fibrosis (Class I)}

Class I markers, also called direct or true markers, are biochemical parameters measurable in the periph- eral blood that express liver matrix constituents or enzymes involved in their regulation, which allow a quantitative assessment of the total amount of hepatic extracellular matrix, and its deposition or removal [19]. Their determination is expensive, and the ability of single markers in the assessment of the severity and progression of liver fibrosis is poor. A systematic review of serum markers of liver fibrosis concluded that panels of markers evaluated in combination are more accurate than single tests [20].

The European Liver Fibrosis (ELF) study evaluated the relationship between different algorithms incorporating serum levels of a panel of direct markers and in- 
dividual histology scores in 1000 patients with a wide range of chronic liver disease [21]. Overall, the algorithm discriminant score allowed a good differentiation between patients with and without cirrhosis at biopsy and might be a promising approach in the future.

\subsection{Panels combining direct and indirect markers}

Some scores combine direct and indirect noninvasive markers to diagnose significant fibrosis or cirrhosis. For example, Fibrometer [22] includes platelets, prothrombin time, AST, $\alpha 2 \mathrm{M}$, age, urea and hyaluronan (HA), and Hepascore [23] includes bilirubin, $\gamma$ GT, TIMP-1, $\alpha 2 \mathrm{M}$, age, and sex. Prospective evaluation [24] has shown improved accuracy of Fibrometer compared to Fibrotest, in particular in diagnosing severe fibrosis and cirrhosis, but further external validation is needed.

\subsection{Prognostic value of serum markers}

Serum markers showed predictive value for liverrelated morbidity and mortality.

The results from ELF study in a subgroup of 120 patients followed-up for 5-8 years suggest that serum markers of fibrosis are as good as liver histology in the prediction of liver related death. In this study, the sensitivity of F3-F4 fibrosis at enrolment in the prediction of liver-related mortality at 8 years was $80.7 \%$, while that of serum markers was $84.0 \%$. In a study in patients with alcoholic liver disease [25], Nojgaard reported that YKL-40 and collagen propetide PIIINP were predictive of short survival and increased relative risk of death. In a cohort of patients with primary biliary cirrhosis treated with UDCA [26], HA was the only independent predictor of poor outcome.

Some studies evaluated the prognostic value of serum markers of fibrosis in patients with cirrhosis. Guechot and colleagues looked at the predictive value of Hyaluronic acid (HA) in a series of patients with HCVcirrhosis, followed-up for a median of 38 months [27]. In this study, HA had a predictive value equivalent to Child-Pugh score for the prediction of severe complications of cirrhosis or death.

\section{Transient Elastography (TE)}

Transient elastography (measured by Fibroscan ${ }^{\circledR}$, Echosens, Paris, France) has been recently developed for the non-invasive assessment of liver stiffness. Mea- surements are performed with an ultrasound transducer probe built on the axis of a vibrator; a vibration of mild amplitude and low frequency is transmitted, inducing a wave that propagates through the liver tissue, and pulse-echo acquisitions are performed to measure the velocity of propagation of the wave, which is directly related to the tissue stiffness. The volume of liver parenchyma which can be studied by Fibroscan is about 100 times greater than that obtained by biopsy, and has therefore a potentially lower sampling error.

Since fibrosis within the liver increases the organ's stiffness, TE has been used to assess the presence of fibrosis and cirrhosis, and has proved an excellent tool in this setting [28]. Liver stiffness has been shown to correlate with fibrosis severity in HCV [29], and in other chronic liver disease [30]. The best cut-off to detect cirrhosis is not exactly defined since it appears to vary according to the etiology of liver disease; however, in a recent prospective study performed in patients with liver disease values over $12.5 \mathrm{kPa}$ strongly suggested cirrhosis [31].

The value of TE in the non-invasive prediction of portal hypertension has also been evaluated. In a study performed in patients with hepatitis $\mathrm{C}$ recurrence after liver transplantation, liver stiffness showed an excellent correlation with fibrosis and with HVPG [32]. In this study, a liver stiffness value $\geqslant 8.74 \mathrm{kPa}$ had a sensitivity and specificity of $90 \%$ and $81 \%$ for the diagnosis of any grade of portal hypertension (HVPG $\geqslant 6 \mathrm{~mm} \mathrm{Hg}$ ).

In addition, in the setting of cirrhosis, liver stiffness has been shown to correlate with the presence of large esophageal varices; specifically, in the study by Kaze$\mathrm{mi}$ and colleagues, a liver stiffness value above $19 \mathrm{kPa}$ predicted the presence of large esophageal varices [33]. In another study published as an abstract [34] the authors found a good direct correlation between HVPG and liver stiffness in a population of uncomplicated alcoholic and HCV-related cirrhotic patients; a cut-off value of $17 \mathrm{kPa}$ had a sensitivity of $90 \%$ for the diagnosis of HVPG over $12 \mathrm{mmHg}$. In two additional studies the cut-off values of respectively 23 and $13.6 \mathrm{kPa}$ had a good capacity to predict the presence of CSPH in patients with chronic liver disease $[35,36]$. It should be underlined that in the study by Vizzutti et al. [35], it was shown that above the threshold value of $13.6 \mathrm{kPa}$ there was not a good correlation between liver stiffness and HVPG, probably since once portal hypertension increases above a the threshold HVPG value of 10$12 \mathrm{mmHg}$ porto-systemic collaterals develop and fibrosis is no longer the only mechanisms inducing portal hypertension, since increase of porto-collateral blood flow importantly contributes [35]. 
Table 2

Main ultrasonographic signs of cirrhosis and portal hypertension

\begin{tabular}{|c|c|c|c|c|}
\hline & & Refs & Sensitivity & Specificity \\
\hline \multicolumn{5}{|c|}{ US signs of cirrhosis } \\
\hline \multirow[t]{6}{*}{ Liver } & Nodular liver surface & $(42 ; 45 ; 79 ; 80)$ & $55-91 \%$ & $82-95 \%$ \\
\hline & Coarse echopattern & $(81 ; 82)$ & $20 \%$ overall & $90 \%$ \\
\hline & & & $51 \% \mathrm{HBV}-\mathrm{HDV}$ & \\
\hline & Left lobe/ right lobe ratio $>1.30$ & $(83)$ & $74 \%$ & $100 \%$ \\
\hline & Caudate lobe/ right lobe ratio $\geqslant 0.65$ (hypertrophy of caudate lobe) & (84) & $43-84 \%$ & $100 \%$ \\
\hline & Reduction of the medial segment of left hepatic lobe & $(85)$ & $74 \%$ & $100 \%$ \\
\hline \multirow{3}{*}{$\begin{array}{l}\text { Hepatic } \\
\text { veins }\end{array}$} & Narrowing and loss of normal phasicity of flow by Doppler & $(86)$ & Not reported & Not reported \\
\hline & Altered straightness & $(87)$ & $97 \%$ & $91 \% 86 \%$ \\
\hline & Nonuniformity of hepatic vein wall echogenicity & & $88 \%$ & \\
\hline $\begin{array}{l}\text { Hepatic } \\
\text { artery }\end{array}$ & Increased diameter & $(88)$ & Not reported & Not reported \\
\hline \multicolumn{5}{|c|}{ US signs of portal hypertension } \\
\hline \multirow{6}{*}{$\begin{array}{l}\text { Portal } \\
\text { venous } \\
\text { system }\end{array}$} & Dilatation of portal vein $(\geqslant 13 \mathrm{~mm})$ & $(16 ; 47)$ & $<50 \%$ & $90-100 \%$ \\
\hline & $\begin{array}{l}\text { Reduction of portal vein blood flow velocity (Max vel }<16 \mathrm{~cm} / \mathrm{s} \text {;) } \\
\text { mean vel }<13 \mathrm{~cm} / \mathrm{s}\end{array}$ & $(89 ; 90)$ & $80-88 \%$ & $80-96 \%$ \\
\hline & Inversion of portal vein blood flow & $(91) \mathrm{d}\} 2\}$ & $\begin{array}{l}\text { Not reported; sign } \\
\text { prevalence: } 8.3 \% \\
\text { of unselected pts }\end{array}$ & $100 \%$ \\
\hline & Increased portal vein congestion index $(\geqslant 0.08)$ & $(49 ; 90)$ & $67-95 \%$ & $100 \%$ \\
\hline & $\begin{array}{l}\text { Dilatation of splenic vein (SV) and superior mesenteric vein (SMV) } \\
(\geqslant 11 \mathrm{~mm})\end{array}$ & $(92 ; 93)$ & $72 \%$ & $100 \%$ \\
\hline & $\begin{array}{l}\text { Reduction of respiratory variation of diameter in SV or SMV }(< \\
40 \%)\end{array}$ & $(47)$ & $79.7 \%$ & $100 \%$ \\
\hline Spleen & Splenomegaly (diameter $>12 \mathrm{~cm}$ and/or area $\geqslant 45 \mathrm{~cm}^{2}$ & (3) & $93 \%$ & $36 \%$ \\
\hline $\begin{array}{l}\text { Splenic } \\
\text { artery }\end{array}$ & Increased resistive index of the intraparenchymal branches $(\geqslant 0.60)$ & (94) & $84.6 \%$ & $70.4 \%$ \\
\hline $\begin{array}{l}\text { Hepatic } \\
\text { artery }\end{array}$ & $\begin{array}{l}\text { Increased resistive index of artery at the porta hepatis }(>0.78) \\
\text { Increased resistive index of the intrahepatic branches }\end{array}$ & (95) & $50 \%$ & $100 \%$ \\
\hline $\begin{array}{l}\text { Renal } \\
\text { artery }\end{array}$ & Increased resistive index of the right interlobar renal artery $(\geqslant 0.65)$ & (94) & $79.5 \%$ & $59.3 \%$ \\
\hline \multirow{2}{*}{\multicolumn{2}{|c|}{$\begin{array}{l}\text { SMA Decrased pulsatility index }(\leqslant 2.70) \\
\text { Presence of porto-systemic collateral circulation }\end{array}$}} & (94) & $85.7 \%$ & $65.2 \%$ \\
\hline & & (58) & $83 \%$ & $100 \%$ \\
\hline
\end{tabular}

In a study recently performed in our unit, TE was tested for the diagnosis of CSPH in the setting of patients with potentially resectable hepatocellular carcinoma. The results suggested that TE is not an ideal method to rule-out or confirm CSPH in this population, and should not be used as a non-invasive surrogate for indicating or contraindicating surgery [37].

Given these observations, it can be suggested that even if high values of liver stiffness at TE are strongly predictive of cirrhosis and of the presence of CSPH, the technique is not accurate enough to assess the severity of portal hypertension.

\section{Ultrasound and colour-Doppler-ultrasound}

Ultrasonography (US) is a non-invasive and inexpensive technique frequently used as first line examina- tion in the diagnosis and follow-up of hepatic diseases (Fig. 1).

Doppler-US is very accurate in diagnosing thrombosis in large vessels. Therefore, it is extremely useful to identify causes of portal hypertension different than cirrhosis, such as portal vein and hepatic veins thrombosis, and should be performed routinely for this purpose at the beginning of the diagnostic work-up of cirrhosis and portal hypertension [38-40].

Findings of cirrhosis on conventional US include changes in liver morphology and signs of portal hypertension (Table 2). US findings are usually highly specific, and can be considered sufficient to confirm the diagnosis [41], so a positive result "rules-in" cirrhosis. On the other hand, the sensitivity of individual US findings is low, indicating that a negative result cannot fully rule-out cirrhosis. 
The most accurate single sign for the diagnosis of cirrhosis, which can be found even in early phases, is nodularity of liver surface [42]; this should be specifically investigated. The use of high frequency transducers increases the diagnostic performance of conventional abdominal US probes, and should be preferred. Few false positive have been described [43].

The combination of nodular liver surface and portal vein mean velocity below $12 \mathrm{~cm} / \mathrm{s}$ holds $80 \%$ accuracy for discriminating between patients with chronic hepatitis with severe fibrosis and those with cirrhosis [44].

In patients with clinical suspicion of cirrhosis and confounding conditions the detection of nodular liver surface is an excellent non-invasive method to rulein cirrhosis, while the combination of US and transient elastography allows the best diagnostic performance [45].

As for the assessment of portal hypertension in cirrhosis, all US signs of portal hypertension are very specific, while their sensitivity is low, especially in compensated cirrhosis; therefore, while the presence of a sign or a combination of signs definitely rules-in portal hypertension, its absence cannot exclude the diagnosis.

Spleen dimension is the US sign most commonly associated to the presence of portal hypertension; contrarily to other signs its sensitivity is high, while its specificity ranges 50-80\% according to different series. It is an independent predictor of esophageal varices, and is associated to $\mathrm{CSPH}$ in compensated cirrhotic patients [3].

The presence of porto-collateral circulation such as paraumbilical vein, spontaneous spleno-renal circulation, dilated left and short gastric veins, and the inversion of flow within the portal system are $100 \%$ specific US signs of CSPH.

Other US signs of CSPH include dilatation of portal vein (diameter $>13 \mathrm{~mm}$ ) [46]; lack or reduced respiratory variations of splenic and superior mesenteric vein diameter [47]; reduced portal vein velocity (maximal and mean velocimetry of portal vein flow, respectively $<16 \mathrm{~cm} / \mathrm{s}$ and $<10-12 \mathrm{~cm} / \mathrm{s}$ ) [48]; increased congestion index of portal vein [49]; altered hepatic venous Doppler pattern [50]; increased intraparenchymal hepatic and splenic artery impedance [51-53]; increased intraparenchymal renal artery impedance [54] and reduced mesenteric artery impedance [55].

HVPG significantly correlates with some US parameters such as portal vein velocity and volume of blood flow [55], hepatic artery resistance index, splenic and renal artery resistance and pulsatility index. However the degree of correlation is only slight to moderate and these parameters can not be used as reliable surrogates of HVPG.

Some US-Doppler parameters hold prognostic value in cirrhosis.

As for the presence of varices and variceal formation, growth and bleeding, models for the prediction of varices of any size or of large varices include portal vein diameter or spleen size in combination with blood tests (platelet count and prothrombin time). Prospective studies in compensated cirrhosis [56,57] initially suggested a good discriminating ability. Nonetheless, validation studies in subsequent series failed to confirm an adequate accuracy for varices prediction. Porto-systemic collaterals such as left gastric vein $>3 \mathrm{~mm}$ and short gastic veins (collaterals at upper spleen half) strongly suggest the presence of esophageal varices [58], and their development/increase in number have been associated with a greater proportion of variceal formation and growth [59]. Similarly, progressive spleen enlargement may predict variceal formation and growth [60].

Congestion index of the portal vein (ratio between the cross-sectional area and blood flow velocity) independently predicted first variceal bleeding in a prospective study in patients with varices [61].

As for the prediction of first clinical decompensation of any kind, spleen enlargement $(>1 \mathrm{~cm})$ on followup might be associated with a higher probability of developing the first clinical decompensation of cirrhosis [60].

A portal vein averaged maximum velocity $<15 \mathrm{~cm} / \mathrm{s}$ was the only variable independently associated with a high risk of non-malignant portal vein thrombosis in a recent prospective study [62].

The presence of porto-systemic collateral circulation predicted hepatocellular carcinoma appearance in a recent study performed in 129 unselected cirrhotic patients [63], probably since porto-systemic collaterals are signs of clinically significant portal hypertension, which is independently related with HCC occurrence [64].

US is highly sensitive in diagnosing ascites, which is the most common clinical decompensation of cirrhosis and holds a severe prognostic significance.

The increase of intrarenal arteriolar RI in patients with cirrhosis is related to arterial vasoconstriction; it is observed in about $40 \%$ of patients with ascites, is accurate for detecting hepato-renal syndrome [65].

A small liver size, spleen size over $14.5 \mathrm{~cm}$, mean portal vein velocity below $10 \mathrm{~cm} / \mathrm{s}$ and loss of pulsatility of hepatic veins have been associated to higher 
mortality on follow-up in patients with compensated cirrhosis [66].

Monitoring of treatment of portal hypertension. There is currently no room for performing US-Doppler monitoring of HVPG response to medical therapy of portal hypertension, since changes of Doppler parameters do not accurately reflect changes in HVPG [66]. However, in a recent study, CDUS pattern at baseline was shown to be different, showing a greater baseline splanchnic vasodilatation (as indicated by a low pulsatility and resistance index in splenic, mesenteric and hepatic artery) in HVPG non-responders than in responders after chronic nadolol treatment [67], and overall the high negative predictive value of Doppler parameters may help to detect non-responders.

On the other hand, US-Doppler is useful in the noninvasive follow-up of transjugular intrahepatic portosystemic shunt (TIPS), and allows saving unnecessary invasive hemodynamics procedures [68].

\section{Second line imaging techniques and new methods needing validation}

Computed tomographic scan (CT) and magnetic resonance (MRI) allow an accurate visualization of the liver parenchyma and the portal venous system.

Three studies demonstrated that single detector or multidetector CT scanning are reliable in detecting large esophageal varices (specificity 90-100\% and sensitivity $84-100 \%$ ), with moderate inter-observer variability; however the sensitivity for small varices detection is lower. A cost-effectiveness analysis showed that straight CT screening of varices was more costeffective than endoscopy screening and than CT followed by endoscopy for patients with small varices on CT [69].

Dynamic contrast-enhanced single-section CT scans and MRI (compartmental analysis of intensity versus time curves for magnetic resonance images of the liver after injection of a gadolinium chelate), and phase contrast MR angiography allow a quantitative measurement of portal [70] and azygos [71] blood flow. Azygos blood flow, as measured by MRI, correlates with the presence of esophageal varices at endoscopy, and with the risk of bleeding from varices. Portal fraction of liver perfusion and mean transit time at MRI have been recently showed to have a good correlation with HVPG [72]. Whether any of these sophisticated and expensive techniques add to clinical, biochemical, US or transient elastography parameters should be evaluated in future studies.

MR elastography (MRE) is a novel method proposed to evaluate liver stiffness. The measurement is obtained by synchronizing motion-sensitive imaging sequences with the application of acoustic waves in tissue media [73]. It has been tested in human subjects, and the preliminary results support its practicability in predicting the stage of fibrosis in patients with chronic liver disease [74]. MRE is repeatable and changes correlate well with changes in tissue fibrosis [75]. MRE has been successfully applied to measure spleen stiffness, which was highly correlated with hepatic stiffness and might have a closer correlation with portal pressure [76].

Although MR elastography has some technical advantage over Fibroscan (no need an acoustical window, a freely-oriented field of view, lack of sensitivity to body habitus) it is more expensive and time consuming and it will only be used as an additional tool in patients that already need to be submitted to MRI for other reasons.

Acoustic radiation force impulse imaging (ARFI) is a novel technology that provides information about the local elasticity of tissues in real-time. Shortduration $(\sim 262 \mu \mathrm{s})$ acoustic pulses are produced and induce the propagation of shear waves which generate minimum displacements within the target tissue. The shear wave velocity (metres per second) is measured in a small portion of the parenchyma $(10 \mathrm{~mm}$ long $\times$ $6 \mathrm{~mm}$ wide). It has the advantage of being integrated in a conventional ultrasound system, so allowing controlling the sampling position within the liver. Recent data suggest that ARFI is as accurate as transient elastography by Fibroscan for fibrosis and cirrhosis detection in patients with chronic liver diseases [77].

\section{References}

[1] P.A. McCormick and N. Nolan, Palpable epigastric liver as a physical sign of cirrhosis: a prospective study, Eur J Gastroenterol Hepatol 16(12) (Nov 2004), 1331-1334.

[2] G. de Bruyn and E.A. Graviss, A systematic review of the diagnostic accuracy of physical examination for the detection of cirrhosis, BMC Med Inform Decis Mak 1 (2001), 6.

[3] A. Berzigotti, R. Gilabert, J.G. Abraldes, C. Nicolau, C. Bru, J. Bosch et al., Noninvasive prediction of clinically significant portal hypertension and esophageal varices in patients with compensated liver cirrhosis, Am J Gastroenterol 103(5) (May 2008), 1159-1167.

[4] A. Gordon, C.A. McLean, J.S. Pedersen, M.J. Bailey and S.K. Roberts, Hepatic steatosis in chronic hepatitis B and C: predictors, distribution and effect on fibrosis, J Hepatol 43(1) (Jul 2005), 38-44. 
[5] P. Perumalswami, D.E. Kleiner, G. Lutchman, T. Heller, B. Borg, Y. Park et al., Steatosis and progression of fibrosis in untreated patients with chronic hepatitis $\mathrm{C}$ infection, Hepatology 43(4) (Apr 2006), 780-787.

[6] V. Leroy, M.N. Hilleret, N. Sturm, C. Trocme, J.C. Renversez, P. Faure et al., Prospective comparison of six non-invasive scores for the diagnosis of liver fibrosis in chronic hepatitis $\mathrm{C}$, J Hepatol 46(5) (May 2007), 775-782.

[7] G. Sebastiani, A. Vario, M. Guido, F. Noventa, M. Plebani, R. Pistis et al., Stepwise combination algorithms of non-invasive markers to diagnose significant fibrosis in chronic hepatitis $\mathrm{C}$, J Hepatol 44(4) (Apr 2006), 686-693.

[8] F. Imbert-Bismut, V. Ratziu, L. Pieroni, F. Charlotte, Y. Benhamou and T. Poynard, Biochemical markers of liver fibrosis in patients with hepatitis $\mathrm{C}$ virus infection: a prospective study, Lancet 357(9262) (7 Apr 2001), 1069-1075.

[9] E. Rossi, L. Adams, A. Prins, M. Bulsara, B.B. de, G. Garas et al., Validation of the FibroTest biochemical markers score in assessing liver fibrosis in hepatitis C patients, Clin Chem 49(3) (Mar 2003), 450-454.

[10] T. Poynard, F. Imbert-Bismut, V. Ratziu, S. Chevret, C. Jardel, J. Moussalli et al., Biochemical markers of liver fibrosis in patients infected by hepatitis $\mathrm{C}$ virus: longitudinal validation in a randomized trial, J Viral Hepat 9(2) (Mar 2002), 128-133.

[11] C.T. Wai, J.K. Greenson, R.J. Fontana, J.D. Kalbfleisch, J.A. Marrero, H.S. Conjeevaram et al., A simple noninvasive index can predict both significant fibrosis and cirrhosis in patients with chronic hepatitis C, Hepatology 38(2) (Aug 2003), 518526.

[12] J. Parkes, I.N. Guha, P. Roderick and W. Rosenberg, Performance of serum marker panels for liver fibrosis in chronic hepatitis C, J Hepatol 44(3) (Mar 2006), 462-474.

[13] A. Braillon, P. Cales, D. Valla, D. Gaudy, P. Geoffroy and D. Lebrec, Influence of the degree of liver failure on systemic and splanchnic haemodynamics and on response to propranolol in patients with cirrhosis, Gut 27(10) (Oct 1986), 1204-1209.

[14] C. Gluud, J.H. Henriksen and C. Nielsen, Prognostic indicators in alcoholic cirrhotic men, Hepatology 8(2) (Mar 1988), 222227.

[15] A.J. Stanley, I. Robinson, E.H. Forrest, A.L. Jones and P.C. Hayes, Haemodynamic parameters predicting variceal haemorrhage and survival in alcoholic cirrhosis, QJM 91(1) (Jan 1998), 19-25.

[16] F. Schepis, C. Camma, D. Niceforo, A. Magnano, S. Pallio, M. Cinquegrani et al., Which patients with cirrhosis should undergo endoscopic screening for esophageal varices detection? Hepatology 33(2) (Feb 2001), 333-338.

[17] A. Zaman, R. Hapke, K. Flora, H.R. Rosen and K. Benner, Factors predicting the presence of esophageal or gastric varices in patients with advanced liver disease, Am J Gastroenterol 94(11) (Nov 1999), 3292-3296.

[18] E. Giannini, F. Botta, P. Borro, D. Risso, P. Romagnoli, A. Fasoli et al., Platelet count/spleen diameter ratio: proposal and validation of a non-invasive parameter to predict the presence of oesophageal varices in patients with liver cirrhosis, Gut 52(8) (Aug 2003), 1200-1205.

[19] G. Sebastiani and A. Alberti, Non invasive fibrosis biomarkers reduce but not substitute the need for liver biopsy, World $J$ Gastroenterol 12(23) (21 Jun 2006), 3682-3694.

[20] K.A. Gebo, H.F. Herlong, M.S. Torbenson, M.W. Jenckes, G. Chander, K.G. Ghanem et al., Role of liver biopsy in management of chronic hepatitis C: a systematic review, Hepatology 36(5 Suppl 1) (Nov 2002), S161-S172.
[21] W.M. Rosenberg, M. Voelker, R. Thiel, M. Becka, A. Burt, D. Schuppan et al., Serum markers detect the presence of liver fibrosis: a cohort study, Gastroenterology 127(6) (Dec 2004), 1704-1713.

[22] P. Cales, F. Oberti, S. Michalak, I. Hubert-Fouchard, M.C. Rousselet, A. Konate et al., A novel panel of blood markers to assess the degree of liver fibrosis, Hepatology 42(6) (Dec 2005), 1373-1381.

[23] L.A. Adams, M. Bulsara, E. Rossi, B. DeBoer, D. Speers, J. George et al., Hepascore: an accurate validated predictor of liver fibrosis in chronic hepatitis $\mathrm{C}$ infection, Clin Chem 51(10) (Oct 2005), 1867-1873.

[24] P. Halfon, Y. Bacq, M.A. De, G. Penaranda, M. Bourliere, D. Ouzan et al., Comparison of test performance profile for blood tests of liver fibrosis in chronic hepatitis C, J Hepatol 46(3) (Mar 2007), 395-402.

[25] C. Nojgaard, J.S. Johansen, E. Christensen, L.T. Skovgaard, P.A. Price and U. Becker, Serum levels of YKL-40 and PIIINP as prognostic markers in patients with alcoholic liver disease, J Hepatol 39(2) (Aug 2003), 179-186.

[26] R.E. Poupon, B. Balkau, J. Guechot and F. Heintzmann, Predictive factors in ursodeoxycholic acid-treated patients with primary biliary cirrhosis: role of serum markers of connective tissue, Hepatology 19(3) (Mar 1994), 635-640.

[27] J. Guechot, L. Serfaty, A.M. Bonnand, O. Chazouilleres, R.E. Poupon and R. Poupon, Prognostic value of serum hyaluronan in patients with compensated HCV cirrhosis, J Hepatol 32(3) (Mar 2000), 447-452.

[28] M. Friedrich-Rust, M.F. Ong, S. Martens, C. Sarrazin, J. Bojunga, S. Zeuzem et al., Performance of transient elastography for the staging of liver fibrosis: a meta-analysis, Gastroenterology 134(4) (Apr 2008), 960-974.

[29] M. Ziol, A. Handra-Luca, A. Kettaneh, C. Christidis, F. Mal, F. Kazemi et al., Noninvasive assessment of liver fibrosis by measurement of stiffness in patients with chronic hepatitis $\mathrm{C}$, Hepatology 41(1) (Jan 2005), 48-54.

[30] C. Corpechot, N.A. El, A. Poujol-Robert, M. Ziol, D. Wendum, O. Chazouilleres et al., Assessment of biliary fibrosis by transient elastography in patients with PBC and PSC, Неpatology 43(5) (May 2006), 1118-1124.

[31] L. Castera, B.B. Le, F. Roudot-Thoraval, P.H. Bernard, J. Foucher, W. Merrouche et al., Early detection in routine clinical practice of cirrhosis and oesophageal varices in chronic hepatitis C: comparison of transient elastography (FibroScan) with standard laboratory tests and non-invasive scores, J Hepatol 50(1) (Jan 2009), 59-68.

[32] J.A. Carrion, M. Navasa, J. Bosch, M. Bruguera, R. Gilabert and X. Forns, Transient elastography for diagnosis of advanced fibrosis and portal hypertension in patients with hepatitis $\mathrm{C}$ recurrence after liver transplantation, Liver Transpl 12(12) (Dec 2006), 1791-1798.

[33] F. Kazemi, A. Kettaneh, G. N'kontchou, E. Pinto, N. GanneCarrie, J.C. Trinchet et al., Liver stiffness measurement selects patients with cirrhosis at risk of bearing large oesophageal varices, J Hepatol 45(2) (Aug 2006), 230-235.

[34] M. Lemoine, S. Katsahian, P. Nahon, N. Ganne-Carrie, F. Kazemi, V. Grando et al., Liver stiffness measurement is correlated with hepatic venous pressure gradient in patients with uncomplicated alcoholic and/or HVC related cirrhosis, Hepatology 44(4(S1)) (1 Oct 2006), 204A.

[35] F. Vizzutti, U. Arena, R.G. Romanelli, L. Rega, M. Foschi, S. Colagrande et al., Liver stiffness measurement predicts severe portal hypertension in patients with HCV-related cirrhosis, Hepatology 45(5) (May 2007), 1290-1297. 
[36] C. Bureau, S. Metivier, J.M. Peron, J. Selves, M.A. Robic, P.A. Gourraud et al., Transient elastography accurately predicts presence of significant portal hypertension in patients with chronic liver disease, Aliment Pharmacol Ther 27(12) (Jun 2008), 1261-1268.

[37] E. Llop, A. Berzigotti, M.E. Reig, E. Erice, J.G. Abraldes, J. Bruix et al., Transient elastography and HVPG measurements in the staging of resectable hepatocellular carcinoma in patients with compensated cirrhosis, Hepatology $\mathbf{5 0}($ Suppl 4) (2009), 438A.

[38] S. Rossi, L. Rosa, V. Ravetta, A. Cascina, P. Quaretti, A. Azzaretti et al., Contrast-enhanced versus conventional and color Doppler sonography for the detection of thrombosis of the portal and hepatic venous systems, AJR Am J Roentgenol 186(3) (Mar 2006), 763-773.

[39] S. Rossi, G. Ghittoni, V. Ravetta, V.F. Torello, L. Rosa, M. Serassi et al., Contrast-enhanced ultrasonography and spiral computed tomography in the detection and characterization of portal vein thrombosis complicating hepatocellular carcinoma, Eur Radiol 18(8) (Aug 2008), 1749-1756.

[40] T. Kok, E.J. van der Jagt, E.B. Haagsma, C.M. Bijleveld, P.L. Jansen and W.J. Boeve, The value of Doppler ultrasound in cirrhosis and portal hypertension, Scand J Gastroenterol Suppl 230 (1999), 82-88.

[41] D.L. Sackett, B.R. Haynes, G.H. Guyatt and P. Tugwell, The interpretation of diagnostic data, in: Clinical Epidemiology: A Basic Science for Clinical Medicine, (2nd ed.), D.L. Sackett, B.R. Haynes, P. Tugwell and G.H. Guyatt, editors Boston, MA, USA: Lippincott Williams \& Wilkins Publishers, 1991, pp. 69-152.

[42] A. Colli, M. Fraquelli, M. Andreoletti, B. Marino, E. Zuccoli and D. Conte, Severe liver fibrosis or cirrhosis: accuracy of US for detection - analysis of 300 cases, Radiology 227(1) (Apr 2003), 89-94.

[43] P. Jha, L. Poder, Z.J. Wang, A.C. Westphalen, B.M. Yeh and F.V. Coakley, Radiologic mimics of cirrhosis, AJR Am J Roentgenol 194(4) (Apr 2010), 993-999.

[44] S. Gaiani, L. Gramantieri, N. Venturoli, F. Piscaglia, S. Siringo, A. D'Errico et al., What is the criterion for differentiating chronic hepatitis from compensated cirrhosis? A prospective study comparing ultrasonography and percutaneous liver biopsy, J Hepatol 27(6) (Dec 1997), 979-985.

[45] A. Berzigotti, J.G. Abraldes, P. Tandon, E. Erice, R. Gilabert, J.C. Garcia-Pagan et al., Ultrasonographic evaluation of liver surface and transient elastography in clinically doubtful cirrhosis, J Hepatol 52 (2010), 846-853.

[46] M. Cottone, G. D’Amico, A. Maringhini, M. Amuso, E. Sciarrino, M. Traina et al., Predictive value of ultrasonography in the screening of non-ascitic cirrhotic patients with large varices, J Ultrasound Med 5(4) (Apr 1986), 189-192.

[47] L. Bolondi, L. Gandolfi, V. Arienti, G.C. Caletti, E. Corcioni, G. Gasbarrini et al., Ultrasonography in the diagnosis of portal hypertension: diminished response of portal vessels to respiration, Radiology 142(1) (Jan 1982), 167-172.

[48] M. Zoli, T. Iervese, C. Merkel, G. Bianchi, D. Magalotti, G. Marchesini et al., Prognostic significance of portal hemodynamics in patients with compensated cirrhosis, J Hepatol 17(1) (Jan 1993), 56-61.

[49] F. Moriyasu, O. Nishida, N. Ban, T. Nakamura, M. Sakai, T. Miyake et al., "Congestion index" of the portal vein, AJR Am J Roentgenol 146(4) (Apr 1986), 735-739.

[50] L. Bolondi, B.S. Li, S. Gaiani, G. Zironi, G. Benzi, V. Santi et al., Liver cirrhosis: changes of Doppler waveform of hepatic veins, Radiology 178(2) (Feb 1991), 513-516.
[51] D. Sacerdoti, C. Merkel, M. Bolognesi, P. Amodio, P. Angeli and A. Gatta, Hepatic arterial resistance in cirrhosis with and without portal vein thrombosis: relationships with portal hemodynamics, Gastroenterology 108(4) (Apr 1995), 11521158.

[52] T. Iwao, A. Toyonaga, K. Oho, C. Tayama, H. Masumoto, T. Sakai et al., Value of Doppler ultrasound parameters of portal vein and hepatic artery in the diagnosis of cirrhosis and portal hypertension [see comments], Am J Gastroenterol 92(6) (Jun 1997), 1012-1017.

[53] M. Bolognesi, D. Sacerdoti, C. Merkel, G. Bombonato and A. Gatta, Noninvasive grading of the severity of portal hypertension in cirrhotic patients by echo-color-Doppler, Ultrasound Med Biol 27(7) (Jul 2001), 901-907.

[54] A. Berzigotti, A. Casadei, D. Magalotti, N. Castaldini, F. Losinno, C. Rossi et al., Renovascular impedance correlates with portal pressure in patients with liver cirrhosis, Radiology 240(2) (Aug 2006), 581-586.

[55] P. Taourel, P. Blanc, M. Dauzat, M. Chabre, J. Pradel, B. Gallix et al., Doppler study of mesenteric, hepatic, and portal circulation in alcoholic cirrhosis: relationship between quantitative Doppler measurements and the severity of portal hypertension and hepatic failure, Hepatology 28(4) (Oct 1998), 932-936.

[56] R. de Franchis, Non-invasive (and minimally invasive) diagnosis of oesophageal varices, J Hepatol 49(4) (Oct 2008), 520-527.

[57] S.N. Sgouros, K.V. Vasiliadis and S.P. Pereira, Systematic review: endoscopic and imaging-based techniques in the assessment of portal haemodynamics and the risk of variceal bleeding, Aliment Pharmacol Ther 30(10) (15 Nov 2009), 965-976.

[58] V. Vilgrain, D. Lebrec, Y. Menu, A. Scherrer and H. Nahum, Comparison between ultrasonographic signs and the degree of portal hypertension in patients with cirrhosis, Gastrointest Radiol 15(3) (1990), 218-222.

[59] A. Berzigotti, C. Merkel, D. Magalotti, C. Tiani, S. Gaiani, D. Sacerdoti et al., New abdominal collaterals at ultrasound: a clue of progression of portal hypertension, Dig Liver Dis 40(1) (Jan 2008), 62-67.

[60] A. Berzigotti, P. Zappoli, D. Magalotti, C. Tiani, V. Rossi and M. Zoli, Spleen enlargement on follow-up evaluation: a noninvasive predictor of complications of portal hypertension in cirrhosis, Clin Gastroenterol Hepatol 6(10) (Oct 2008), 1129-1134.

[61] S. Siringo, L. Bolondi, S. Gaiani, S. Sofia, G. Zironi, A. Rigamonti et al., Timing of the first variceal hemorrhage in cirrhotic patients: prospective evaluation of Doppler flowmetry, endoscopy and clinical parameters, Hepatology 20(1 Pt 1) (Jul 1994), 66-73.

[62] M.A. Zocco, S.E. Di, C.R. De, M. Novi, M.E. Ainora, F. Ponziani et al., Thrombotic risk factors in patients with liver cirrhosis: correlation with MELD scoring system and portal vein thrombosis development, J Hepatol 51(4) (Oct 2009), 682-689.

[63] G. Tarantino, V. Citro, P. Conca, A. Riccio, M. Tarantino, D. Capone et al., What are the implications of the spontaneous spleno-renal shunts in liver cirrhosis? BMC Gastroenterol 9 (2009), 89.

[64] C. Ripoll, R.J. Groszmann, G. Garcia-Tsao, J. Bosch, N. Grace, A. Burroughs et al., Hepatic venous pressure gradient predicts development of hepatocellular carcinoma independently of severity of cirrhosis, J Hepatol 50(5) (May 2009), 923-928.

[65] A. Maroto, A. Gines, J. Salo, J. Claria, P. Gines, L. Anibarro et al., Diagnosis of functional kidney failure of cirrhosis 
with Doppler sonography: prognostic value of resistive index, Hepatology 20(4 Pt 1) (Oct 1994), 839-844.

[66] A. Berzigotti, F. Schepis and J.C. Garcia-Pagan, Monitoring treatment of cirrhosis and portal hypertension: non-invasive means, in: Advances in the Therapy of Liver Diseases, (1st ed.), V. Arroyo, A. Sanchez-Fueyo, J. Fernandez-Gomez, X. Forns, P. Gines and J. Rodes, editors, Barcelona, Spain: Ars Medica, 2007, pp. 39-52.

[67] A. Berzigotti, M.F. Rinaldi, D. Magalotti, M.C. Morelli, P. Zappoli, P. Andreone et al., Primary prophylaxis with nadolol in cirrhotic patients: Doppler patterns of splanchnic hemodynamics in good and poor responders, $J$ Hepatol 44(2) (Feb 2006), 310-316.

[68] J.G. Abraldes, R. Gilabert, J. Turnes, C. Nicolau, A. Berzigotti, J. Aponte et al., Utility of color Doppler ultrasonography predicting tips dysfunction, Am J Gastroenterol 100(12) (Dec 2005), 2696-2701.

[69] R. de Franchis, Non-invasive (and minimally invasive) diagnosis of oesophageal varices, J Hepatol 49(4) (Oct 2008), $520-527$.

[70] R. Materne, L. Annet, S. Dechambre, C. Sempoux, A.M. Smith, C. Corot et al., Dynamic computed tomography with low- and high-molecular-mass contrast agents to assess microvascular permeability modifications in a model of liver fibrosis, Clin Sci (Lond) 103(2) (Aug 2002), 213-216.

[71] B.E. Van Beers, R. Materne, L. Annet, L. Hermoye, C. Sempoux, F. Peeters et al., Capillarization of the sinusoids in liver fibrosis: noninvasive assessment with contrast-enhanced MRI in the rabbit, Magn Reson Med 49(4) (Apr 2003), 692-699.

[72] L. Annet, R. Materne, E. Danse, J. Jamart, Y. Horsmans and B.E. Van Beers, Hepatic flow parameters measured with MR imaging and Doppler US: correlations with degree of cirrhosis and portal hypertension, Radiology 229(2) (Nov 2003), 409414.

[73] A. Manduca, T.E. Oliphant, M.A. Dresner, J.L. Mahowald, S.A. Kruse, E. Amromin et al., Magnetic resonance elastography: non-invasive mapping of tissue elasticity, Med Image Anal 5(4) (Dec 2001), 237-254.

[74] L. Huwart, F. Peeters, R. Sinkus, L. Annet, N. Salameh, L.C. ter Beek et al., Liver fibrosis: non-invasive assessment with MR elastography, NMR Biomed 19(2) (Apr 2006), 173-179.

[75] C.D. Hines, T.A. Bley, M.J. Lindstrom and S.B. Reeder, Repeatability of magnetic resonance elastography for quantification of hepatic stiffness, J Magn Reson Imaging 31(3) (Mar 2010), 725-731.

[76] J.A. Talwalkar, M. Yin, S. Venkatesh, P.J. Rossman, R.C. Grimm, A. Manduca et al., Feasibility of in vivo MR elastographic splenic stiffness measurements in the assessment of portal hypertension, AJR Am J Roentgenol 193(1) (Jul 2009), 122-127.

[77] M. Friedrich-Rust, K. Wunder, S. Kriener, F. Sotoudeh, S. Richter, J. Bojunga et al., Liver fibrosis in viral hepatitis: noninvasive assessment with acoustic radiation force impulse imaging versus transient elastography, Radiology 252(2) (Aug 2009), 595-604.

[78] R. Smith-Bindman, J. Lipson, R. Marcus, K.P. Kim, M. Mahesh, R. Gould et al., Radiation dose associated with common computed tomography examinations and the associated lifetime attributable risk of cancer, Arch Intern Med 169(22) (14 Dec 2009), 2078-2086.

[79] A. Di Lelio, C. Cestari, A. Lomazzi and L. Beretta, Cirrhosis: diagnosis with sonographic study of the liver surface,
Radiology 172(2) (Aug 1989), 389-392.

[80] V. Simonovsky, The diagnosis of cirrhosis by high resolution ultrasound of the liver surface, Br J Radiol 72(853) (Jan 1999), 29-34.

[81] E. Caturelli, L. Castellano, S. Fusilli, B. Palmentieri, G.A. Niro, C. del Vecchio-Blanco et al., Coarse nodular US pattern in hepatic cirrhosis: risk for hepatocellular carcinoma, Radiology 226(3) (Mar 2003), 691-697.

[82] A.E. Joseph, S.H. Saverymuttu, S. al-Sam, M.G. Cook and J.D. Maxwell, Comparison of liver histology with ultrasonography in assessing diffuse parenchymal liver disease, Clin Radiol 43(1) (Jan 1991), 26-31.

[83] A.K. Goyal, D.S. Pokharna and S.K. Sharma, Ultrasonic diagnosis of cirrhosis: reference to quantitative measurements of hepatic dimensions, Gastrointest Radiol 15(1) (1990), 32-34.

[84] A. Giorgio, P. Amoroso, G. Lettieri, P. Fico, S.G. de, L. Finelli et al., Cirrhosis: value of caudate to right lobe ratio in diagnosis with US, Radiology 161(2) (Nov 1986), 443-445.

[85] M. Lafortune, L. Matricardi, A. Denys, M. Favret, R. Dery and G. Pomier-Layrargues, Segment 4 (the quadrate lobe): a barometer of cirrhotic liver disease at US, Radiology 206(1) (Jan 1998), 157-160.

[86] L. Bolondi, S. Li Bassi, S. Gaiani, G. Zironi, G. Benzi, V. Santi et al., Liver cirrhosis: changes of Doppler waveform of hepatic veins, Radiology 178(2) (Feb 1991), 513-516.

[87] S. Vessal, S. Naidoo, J. Hodson, D.L. Stella and R.N. Gibson, Hepatic vein morphology: a new sonographic diagnostic parameter in the investigation of cirrhosis? J Ultrasound Med 28(9) (Sep 2009), 1219-1227.

[88] R. Toni, L. Bolondi, S. Gaiani, G. Re, L. Calabrese, G. Cavalli et al., Accessory ultrasonographic findings in chronic liver disease: diameter of splenic and hepatic arteries, fasting gallbladder volume, and course of left portal vein, J Clin Ultrasound 13(9) (Nov 1985), 611-618.

[89] G. Zironi, S. Gaiani, D. Fenyves, A. Rigamonti, L. Bolondi and L. Barbara, Value of measurement of mean portal flow velocity by Doppler flowmetry in the diagnosis of portal hypertension, J Hepatol 16(3) (Nov 1992), 298-303.

[90] K. Haag, M. Rossle, A. Ochs, M. Huber, V. Siegerstetter, M. Olschewski et al., Correlation of duplex sonography findings and portal pressure in 375 patients with portal hypertension, AJR Am J Roentgenol 172(3) (Mar 1999), 631-635.

[91] S. Gaiani, L. Bolondi, B.S. Li, G. Zironi, S. Siringo and L. Barbara, Prevalence of spontaneous hepatofugal portal flow in liver cirrhosis. Clinical and endoscopic correlation in 228 patients, Gastroenterology 100(1) (Jan 1991), 160-167.

[92] M. Zoli, C. Dondi, G. Marchesini, M.R. Cordiani, A. Melli and E. Pisi, Splanchnic vein measurements in patients with liver cirrhosis: a case-control study, J Ultrasound Med 4(12) (Dec 1985), 641-646.

[93] A.K. Goyal, D.S. Pokharna and S.K. Sharma, Ultrasonic measurements of portal vasculature in diagnosis of portal hypertension. A controversial subject reviewed, J Ultrasound Med 9(1) (Jan 1990), 45-48.

[94] F. Vizzutti, U. Arena, L. Rega, R.G. Romanelli, S. Colagrande, S. Cuofano et al., Performance of Doppler ultrasound in the prediction of severe portal hypertension in hepatitis $\mathrm{C}$ virusrelated chronic liver disease, Liver Int 27(10) (Dec 2007), 1379-1388.

[95] M.B. Alpern, J.M. Rubin, D.M. Williams and P. Capek, Porta hepatis: duplex Doppler US with angiographic correlation, Radiology 162(1 Pt 1) (Jan 1987), 53-56. 


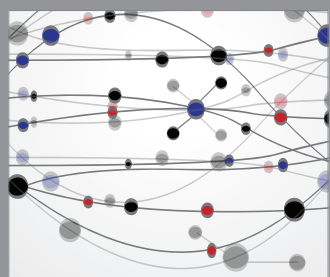

The Scientific World Journal
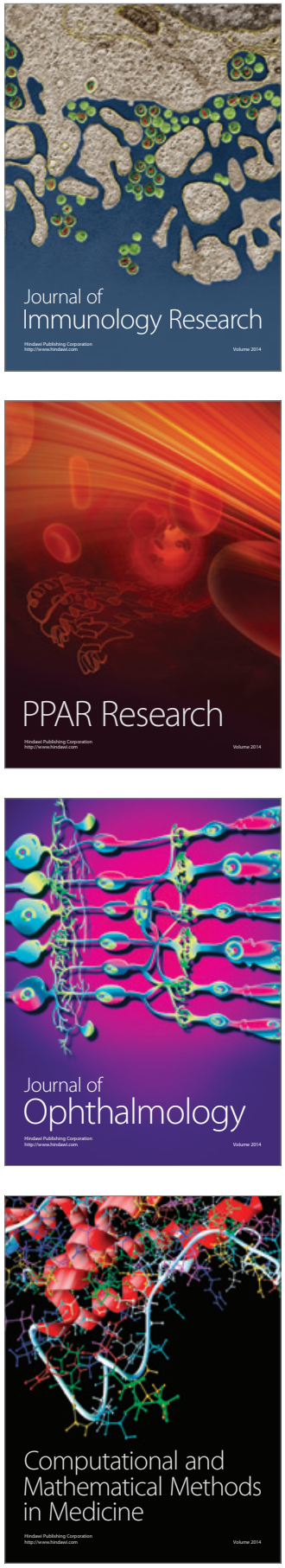

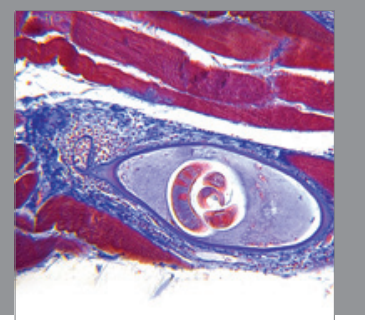

Gastroenterology

Research and Practice
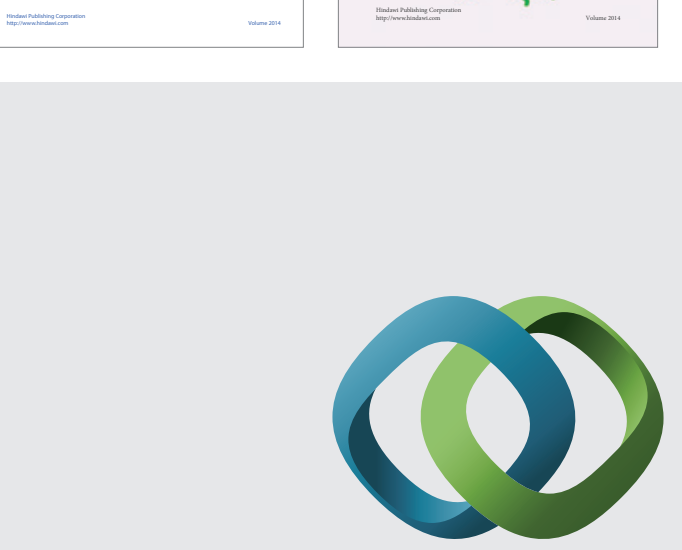

\section{Hindawi}

Submit your manuscripts at

http://www.hindawi.com
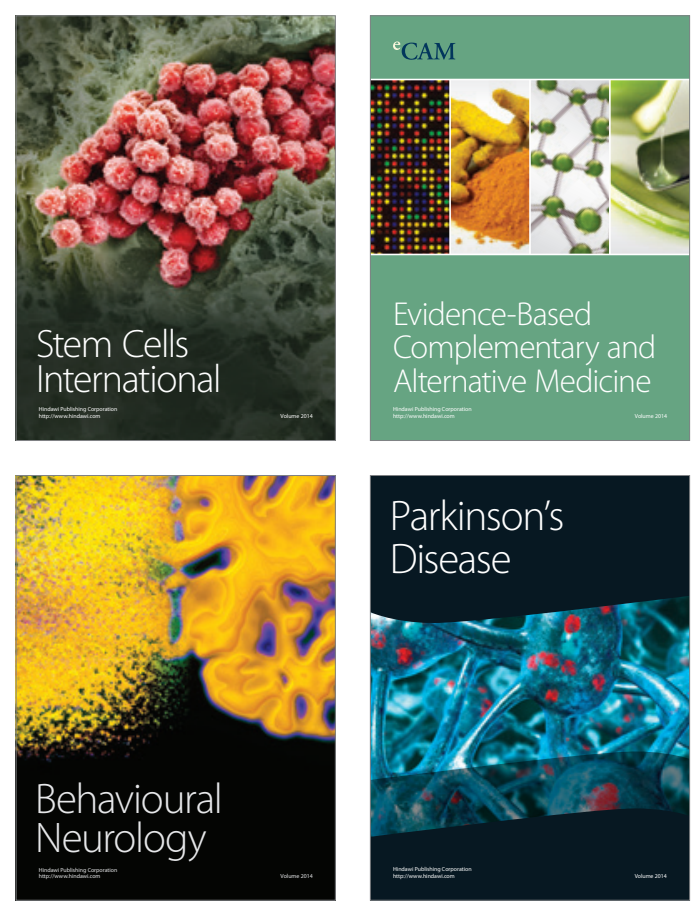

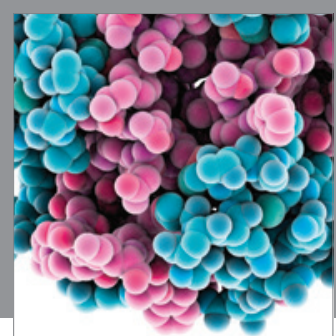

Journal of
Diabetes Research

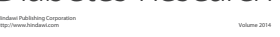

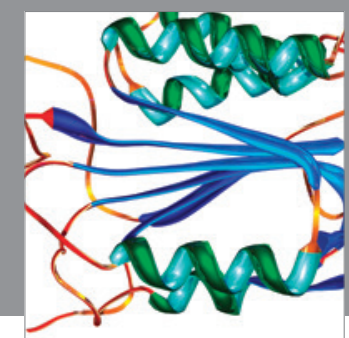

Disease Markers
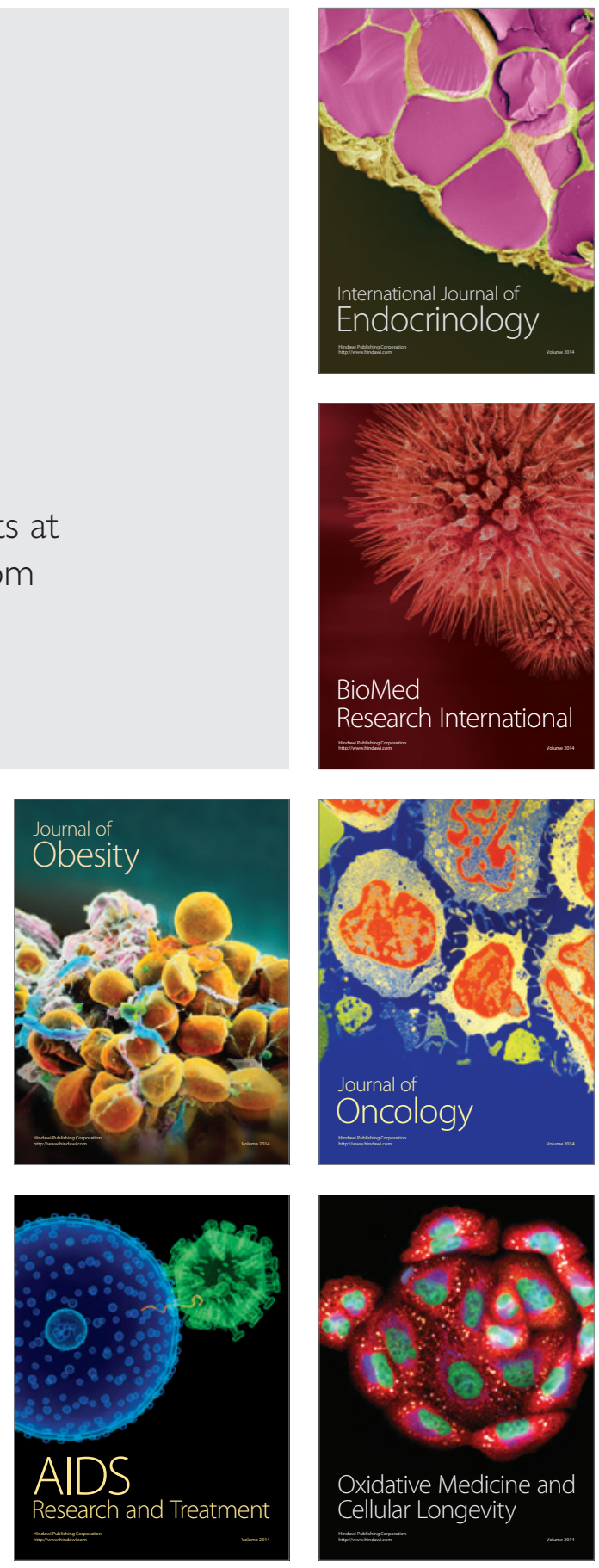